\title{
Morphogenetic callus and multiple shoot regeneration; and thin layer chromatography studies of Tylophora indica (Burn.f) Merill
}

\author{
K. Kalimuthu* and S. Jeyaraman \\ Plant Tissue Culture Laboratory, Department of Botany, PG and Research, Government Arts College, \\ Coimbatore -641018 , India. \\ Accepted 2 April, 2012
}

\begin{abstract}
An in vitro propagation protocol for an important ethnomedicinal plant, Tylophora indica (Burn.f) Merill has been developed. The effect of 0.5 to $3.0 \mathrm{mg} / \mathrm{L}$ benzo[a]pyrene (BAP) alone on in vitro multiple shoot production from leaf explants was studied. The maximum number of indirect regeneration of multiple shoots (7 shoots) was achieved from leaf explants on MS medium enriched with $2.5 \mathrm{mg} / \mathrm{L}$ BAP alone. Furthermore, large-scale shoot formation ( 25 shoots) was achieved by reported sub-culturing of leaf callus on shoot regeneration medium (MS $+2.5 \mathrm{mg} / \mathrm{L} \mathrm{BAP)}$. The best root induction (97\%) was achieved on MS medium enriched with indole-3-butyric acid (IBA) $(0.5 \mathrm{mg} / \mathrm{L})$. The plantlets were hardened off and more than $95 \%$ of survival plants were released to the shade house. The presence of alkaloids in vivo and in vitro samples was clearly detected.
\end{abstract}

Key words: Tylophora indica, leaf derived callus, regeneration, morphogenetic.

\section{INTRODUCTION}

Tylophora indica (Burm f.) Merrill (Asclepiadaceae) is a threatened medicinal climber native to the plain and hill forests of eastern and southern India up to an altitude of 900 m (Suleka Rani and Rana, 2010). The plant has been traditionally exploited by tribes in certain regions of India for the treatment of various ailments (Anonymous, 1976). The plant contains several phenanthroindolizidine alkaloids and pharmacological investigations have confirmed the anti-asthmatic effects of its leaf extracts (Shivpuri et al., 1972). The major alkaloid presenttylophorine- has been reported to have immunosuppressive, anti-inflammatory (Gopalakrishnan et al., 1980) and antitumor properties. The powdered leaves, stems and roots also contain other minor alkaloids including tylophorine cryptopleurine, antofine and ficuseptine $\mathrm{C}$ which are pharmacologically active and anticancer tylophorinidine has also been isolated from the

\footnotetext{
${ }^{*}$ Corresponding author. E-mail: k_kalimuthu@rediffmail.com.
}

roots of three-year old plant (Mulchandani et al., 1971). Thus the plant is in great demand for the production of traditional and modern medicines.

Owing to large scale and uncontrolled exploitation of this natural resource in order to meet its ever-increasing demand in the pharmaceutical applications, wild stock of this plant species has been markedly depleted over past few years. Unfortunately, efforts for its replenishment by conventional cultivation have been handicapped because it is not amenable to vegetative propagation through cuttings, and propagation through seeds would result in variation. Therefore, the application of a reliable, in vitro clonal propagation system would provide an alternative method of propagation to meet the pharmaceutical needs and for effective conservation of this precious plant species. It is advantageous for conservation of germ plasm and multiplication of best genotypes with high alkaloid contents. Although, micro propagation of $T$. indica by axillary shoot induction and adventitious shoot production (Sharma and Chandel, 1992; Faisal et al., 2007; Chaudhuri et al., 2004) and callus-mediated 
Table 1. Effect of MS medium and different concentrations of BAP on callus inductions and shoot formation.

\begin{tabular}{cccclc}
\hline S/N & $\begin{array}{c}\text { MS medium + BAP } \\
\text { mg/L }\end{array}$ & $\begin{array}{c}\text { \% of explant } \\
\text { producing callus }\end{array}$ & $\begin{array}{c}\text { \% of same callus } \\
\text { forming shoots }\end{array}$ & $\begin{array}{l}\text { Nature of the } \\
\text { callus }\end{array}$ & $\begin{array}{c}\text { Days taken for } \\
\text { callus induction }\end{array}$ \\
\hline 1 & 0.5 & $40.0^{\mathrm{a}}$ & - & Green friable & 15 \\
2 & 1.0 & $45.0^{\mathrm{b}}$ & - & Green friable & 12 \\
3 & 1.5 & $60.0^{\mathrm{c}}$ & $5.0^{\mathrm{a}}$ & Green friable & 10 \\
4 & 2.0 & $63.5^{\mathrm{d}}$ & $25.0^{\mathrm{b}}$ & Green friable & 8 \\
5 & 2.5 & $90.0^{\mathrm{e}}$ & $90.0^{\mathrm{c}}$ & Friable and dark green & 7 \\
6 & 3.0 & $75.0^{\mathrm{f}}$ & $60.0^{\mathrm{d}}$ & Friable and dark green & 7 \\
\hline
\end{tabular}

Values are means of 5 samples. A column mean followed by a common superscript letter are not significantly different at the $5 \%$ level (DMRT).

somatic embryogenesis from leaf (Jayanthi and Mandal, 2001; Chandrasekhar et al., 2006; Manjula et al., 2000) and inter nodal (Thomas, 2006) explants have been previously reported; these studies were of preliminary nature, and more studies and further refinements of techniques were absolutely necessary. Hence in the present investigation, we evaluated various factors influencing in vitro axillary shoot proliferation and resulted in an efficient and reproducible procedure for rapid clonal multiplication of this pharmaceutically important plant species. Hence, the present investigation was launched to maximize micropropagation rate of $T$. indica by using two types of media and to compare the alkaloids present in the in vivo and in vitro plants and callus of $T$. indica by the way of thin layer chromatography (TLC).

\section{MATERIALS AND METHODS}

Leaves from the young and healthy branches of $T$. indica were used as explant. Since the explant collected from the natural habitats failed to produce callus due to the presence of systematic fungus, the leaves were collected from the pot cultured individuals which were maintained in a shade house. The collected young leaves were washed with tap water twice and then treated with $5 \%$ teepol solution for 10 min for surface sterilization and rinsed with tap water. To eliminate the fungal contamination, explants were treated with Bavistin (1\%) (v/v) fungicide (10\%) for $20 \mathrm{~min}$ and rinsed with tap water. Furthermore, surface sterilization was carried out by dipping the explants in $70 \%$ alcohol for $30 \mathrm{~s}$ and $0.12 \%$ $\mathrm{HgCl}_{2}$ for $3 \mathrm{~min}$ followed by three to four rinses in double distilled sterilized water. MS (Murashige and Skoog, 1962) basal medium containing $3 \%$ sucrose solidified with $1 \%$ agar (tissue culture grade, Himedia, India) was used. The $\mathrm{pH}$ of the medium was adjusted within the range of 5.8 to 5.9 , prior to the addition of agar. The explants were culturing in culture bottles containing $30 \mathrm{ml}$ MS basal medium supplemented with different concentration of BAP for callus induction. Cultures were incubated at $25 \pm 2^{\circ} \mathrm{C}$ for $16 \mathrm{~h}$ photoperiod from cool white fluorescent tubes giving 2000 lux at culture level. Callus obtained from these primary cultures were transferred to MS (Murashige and Skoog, 1962) containing different concentration of benzo[a]pyrene (BAP). Shoot buds that originated from leaf callus after 20 days were subcultured. Data on shoot proliferation efficiency were recorded after 10 weeks of culture. Proliferated shoots were transferred to MS with different concentration of BAP, NAA for adventitious root formation. For hardening, pot culture experiment was conducted using a mixture of hardening media (decomposed coir waste + perlite + compost 1:1:1) and survivability rates were determined after 20 days of hardening. Five replicates were maintained for the culturing experiment of callus formation and sub culturing experiment of shoot and root formation.

\section{Thin layer chromatography}

Forty days old $T$. indica callus, four month old in vitro plants and in vivo plants were collected and used for thin layer chromatography studies. In vitro, in vivo and callus of $T$. indica were dried at ambient temperature (shade dried) ground through a Wiley mill equipped with $2 \mathrm{~mm}$ sieve and stored at room temperature $\left(28 \pm 1^{\circ} \mathrm{C}\right)$ in air tight polybag until extraction. $10 \mathrm{~g}$ of the powdered samples were moistened with $10 \mathrm{ml}$ of $1 \%$ ammonia solution for $1 \mathrm{~h} .10 \mathrm{ml}$ of methanol was added, extracted by heating on a water bath at $45^{\circ} \mathrm{C}$ for $30 \mathrm{~min}$ continuously. The residue was extracted with $10 \mathrm{ml}$ methanol continuously until it turns to colourless. The extract is allowed to dry in open air. The final volume was made up to $1 \mathrm{ml}$ (Harbourne, 1973; Wagner and Bladt, 1996).

\section{RESULTS AND DISCUSSION}

\section{Callus initiation}

Callus induction was observed on MS medium containing different concentration and combinations of BAP (0.5 to $3.0 \mathrm{mg} / \mathrm{L}$ ) within 8 to 10 days of incubation of the leaf explants (Figure $1 \mathrm{~A}$ ). There was a wide range of variation on percentage of callus induction (0 to 90) according to the concentration of hormones (Table 1). About $90 \%$ of leaf produced callus and shoot formation on MS medium containing BAP. The caulogenic effect of BAP, observed in the present study is in consonance with other reports (Batra et al., 2002; Jayanthi and Mandal, 2001). Best growth of callus however occurred on MS + BAP (2.5 $\mathrm{mg} / \mathrm{L})$, followed by MS + BAP (3.0 mg/L). The other concentration of BAP was also effective but not at the level of previous combination. Similar observation was reported in T. indica (Faisal et al., 2007), that BAP + NAA were basically involved at the development of callus. Callusing started at the cut ends or along the entire surface after 10 days of culture and after 2 to 3 weeks, the entire segment turned with a mass of green soft and friable callus (Figure 1A). 
Table 2. Effect of MS medium and growth regulators on root induction.

\begin{tabular}{ccccc}
\hline S/N & MS medium + IBA mg/L & No. of days for rooting & Rooting frequency & Root length/explant (cm) \\
\hline 1 & 0.5 & $10-14^{\mathrm{a}}$ & $32.0^{\mathrm{a}}$ & $2.3^{\mathrm{a}}$ \\
2 & 1.0 & $10-12^{\mathrm{b}}$ & $40.0^{\mathrm{b}}$ & $2.8^{\mathrm{b}}$ \\
3 & 1.5 & $10-12^{\mathrm{c}}$ & $40.0^{\mathrm{cb}}$ & $2.9^{\mathrm{cb}}$ \\
4 & 2.0 & $9-10^{\mathrm{d}}$ & $42.0^{\mathrm{db}}$ & $3.2^{\mathrm{d}}$ \\
5 & 2.5 & $6-7^{\mathrm{e}}$ & $97.0^{\mathrm{e}}$ & $5.5^{\mathrm{e}}$ \\
6 & 3.0 & $6-7^{\mathrm{f}}$ & $75.0^{\mathrm{f}}$ & $3.9^{\mathrm{f}}$ \\
\hline
\end{tabular}

Values are means of 5 samples. A column mean followed by a common superscript letter are not significantly different at the $5 \%$ level (DMRT).

Table 3. Effect of different potting media on the hardening of in vitro plantlets.

\begin{tabular}{clccc}
\hline S/N & Media composition & No. of plant & No. of plants survival & Plantlet survival rate (\%) \\
\hline 1 & Red soil + sand & 20 & $5^{\mathrm{a}}$ & $25^{\mathrm{a}}$ \\
2 & Vermicompost & 20 & $12^{\mathrm{b}}$ & $60^{\mathrm{b}}$ \\
3 & Decomposed coir waste soil & 20 & $16^{\mathrm{c}}$ & $80^{\mathrm{c}}$ \\
4 & Hardening + decomposed coir waster & 20 & $19^{\mathrm{d}}$ & $95^{\mathrm{d}}$ \\
\hline
\end{tabular}

Values are means of 5 samples. A column mean followed by a common superscript letter are not significantly different at the $5 \%$ level (DMRT).

\section{Shoot proliferation}

Shoot differentiation occurred on the same medium (BAP $2.5 \mathrm{mg} / \mathrm{L})$ or when calli was transferred to fresh medium. 15 to 20 shoots were induced per explants within 20 to 25 days. The shoot elongated and grew well and developed many leaves. For shoot, proliferation cytokines are one of the major important factors affecting the response (Bhojwani, 1980). A wide range of cytokinins like BAP, 2ip and kinetin have been employed in shoot proliferation (Bhojwani and Razdan, 1982). However, a wide survey of literature suggests that BAP is the most reliable and effective cytokinins. The shoot proliferation effect of BAP observed in the present study is in consonance with other reports (Rathore et al., 2008).

\section{Root induction}

Induction and development of roots at the base of in vitro grown shoots is an essential and indispensable step to establish tissue culture derived plantlets to the soil. Shoots thus formed were excised and subjected to rooting induction (Table 2 ).

Amongst the three auxins (NAA, IAA and IBA) tried for rooting, IBA $(0.5 \mathrm{mg} / \mathrm{L})$ proved best for the induction of roots from the base of regenerated shoots. Use of NAA resulted in callusing at the base of shoots. Similarly the essentiality of IBA for root induction has been demonstrated in T. indica (Faisal et al., 2005, 2007; Thomas,
2009).

\section{Hardening and acclimatization}

Hardening is a crucial step to transplantation of plant to soil. The well developed plantlets were transplanted in net pot containing autoclaved hardening media (Table 3). The plants were kept in high relative humidity ( $\mathrm{RH} 90 \%$ ) for one week. After one week they were brought to lower $\mathrm{RH}(60 \%)$ for further hardening for another two weeks. Afterwards the hardened plants were repotted in polythene bags containing red soil, sand and compost (1:1:1) and kept in the field for developing into mature plants. The hardened plants were transferred to field with a survival rate of $95 \%$ (Table 3 ). All plants had normal leaf development and no morphological variation was noticed (Figure 1).

\section{Alkaloid determination}

Specific extraction of alkaloids from the fresh extract of $T$. indica in vitro, in vivo and callus were performed using $1 \%$ of ammonia solution and $100 \%$ methanol. All the three samples were loaded in the Silica Gel (mesh size: 60 to $120 \mathrm{ng}$ ) coated TLC plats are analyzed. Alkaloids as separates to bands in vivo and in vitro (Figure 2 and Table 4) having the $h R_{f}$ value of 59 and 51 , respectively.

After spraying Dragendorff's reagent and enhanced 
Table 4. Bands observed from the in vivo, in vitro and callus plant sample of the Tylophora indica.

\begin{tabular}{|c|c|c|c|c|}
\hline$S / N$ & No. of band & Colour & $R_{\mathrm{f}}$ value & $h R_{f}$ value \\
\hline \multicolumn{5}{|c|}{ In vivo } \\
\hline 1 & \multirow{2}{*}{2} & Reddish brown & 0.51 & 51 \\
\hline 2 & & Brown & 0.59 & 59 \\
\hline \multicolumn{5}{|c|}{ In vitro } \\
\hline 1 & \multirow{2}{*}{2} & Reddish brown & 0.51 & 51 \\
\hline 2 & & Brown & 0.59 & 59 \\
\hline \multicolumn{5}{|c|}{ Callus } \\
\hline \multirow{2}{*}{\multicolumn{2}{|c|}{ No presence of band }} & - & - & - \\
\hline & & - & - & - \\
\hline
\end{tabular}
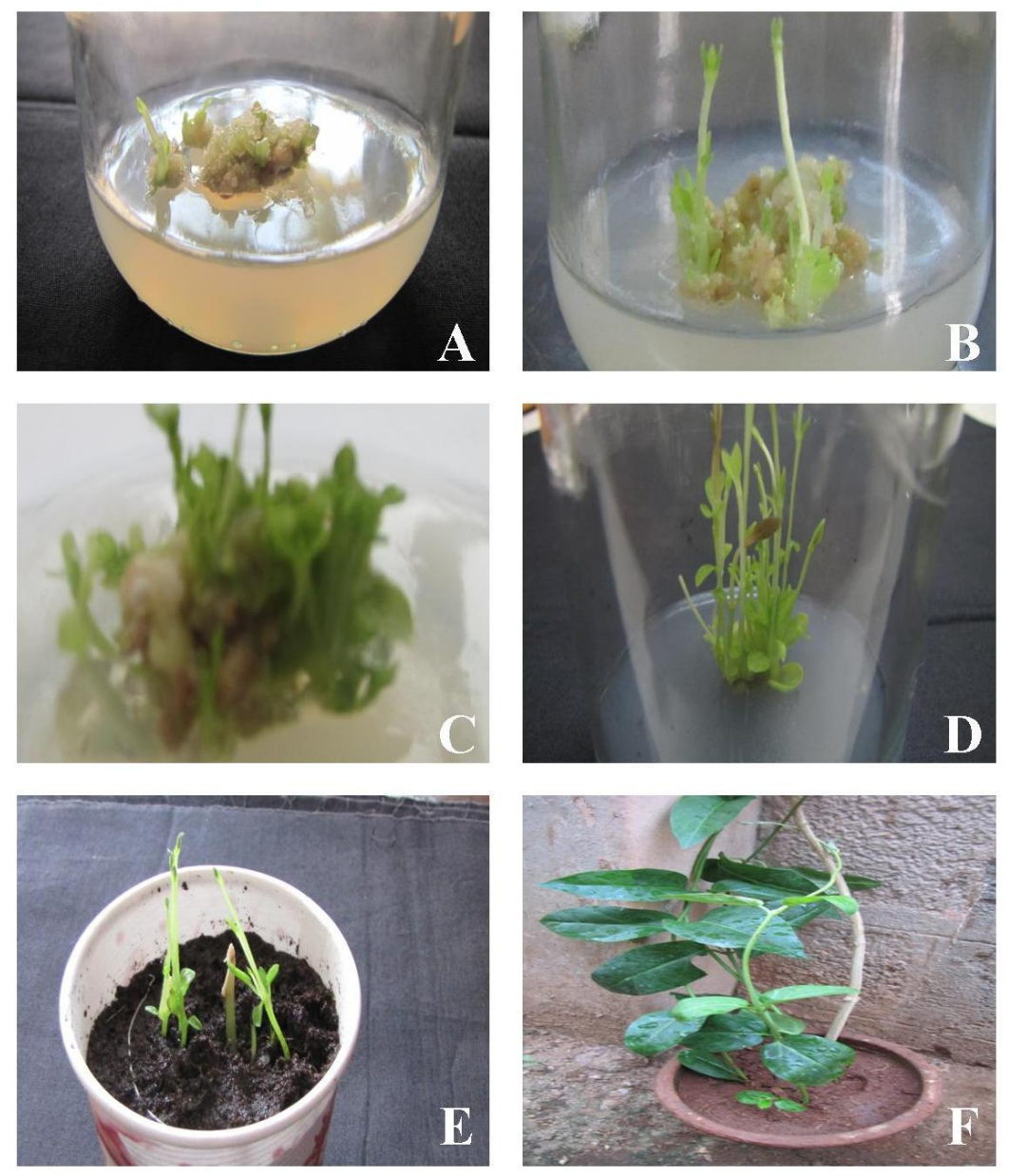

Figure 1. (A) Callus formation from leaf; (B) shoot initiation; (C) multiple shoot formation; (D) shoot elongation; $(E)$ primary hardening; $(F)$ potted plant.

with $10 \%$ of sodium nitrite, the presence of alkaloids in vivo and in vitro samples of clearly detected. $\mathrm{hR}_{\mathrm{f}}$ value of 59 and 51 clearly detected in both in vitro and in vivo samples indicated to bands, were one and the same. The absence of any band(s) in callus presumed that alkaloids may not be synthesized in the 40 day's old studied callus. 


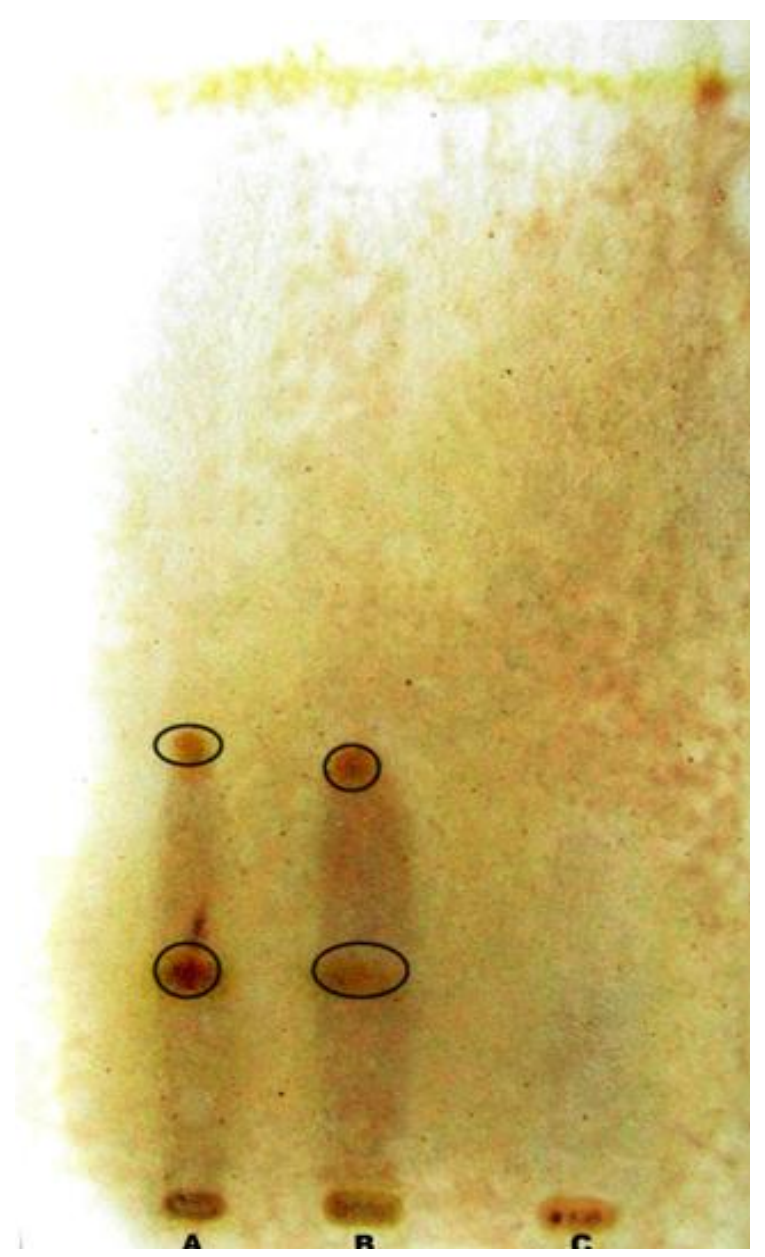

Figure 2. Thin layer chromatogram developed for alkaloids. (A) In vivo sample; B) in vitro sample; (C) callus sample.

$T$. indica is of economic interest for its wide range of pharmacological activity and pesticide property. It is hoped that the protocol reported here to induce multiple shoots may provide a more homogenous source of plants. Present work reports an efficient and easy-to-use protocol for multiplication of medicinal herb, $T$. indica through tissue culture.

\section{ACKNOWLEDGEMENT}

The authors are grateful to the University Grants Commission (UGC), New Delhi for financial assistance to carry out the work.

\section{REFERENCES}

Anonymous (1976). The wealth of India, Rao materials, Vol. X: Publications and Information Directorate. CSIR, New Delhi, India. Bhojwani SS (1980). In vitro propagation of garlic by shoot proliferation. Sci. Hortic. 13:47-52.
Bhojwani SS. Razdan MK (1982). Plant tissue culture: Theory and practice. Elsevier Sci .Publ. Amsterdam, pp. 1-520.

Chandrasekhar T, Mohammad Hussain T,Rama Gopal G, Srinivasa Rao JV (2006). Somatic embryogenesis of Tylophora indica (Burm.f.) Merril., an important medicinal plant. Int. J. Appl. Sci. Eng. 4(1):3340.

Chaudhuri K N, Ghosh B, Jha S (2004). The root: a potential new source of competent cells for high-frequency regenerationin Tylophora indica. Plant Cell Rep. 22(10):73-74.

Faisal M, Ahmad N, Anis M (2007). An efficient micropropagation system for Tylophora indica: An endangered, medicinally important plant. Plant Biotechnol. Rep. 1:155-161.

Faisal M, Sigh S, Anis M (2005). In vitro regeneration and plant establishment of Tylophora indica petiole callus culture. In vitro Cell. Dev. Bio-plant. 41:511-515.

Gopalakrishnan C, Shankaranarayanan D, Nazimudeen SK (1980). Effect of tylophorine, a major alkaloid of Tylophora indica, on immune pathological and inflammatory reactions. Indian J. Med. Res. 71:940-948.

Jayanthi M, Mandal PK (2001). Plant regeneration through somatic embryogenesis and RAPD analysis of regenerated plants in Tylophora indica (Burm. f. Merrill.). In vitro Cell. Dev. Biol. Plant. 37:576-580.

Manjula S, Job A, Nair GM (2000). Somatic embryogenesis from leaf derived callus of Tylophora indica (Burm. f.) Merrill. Indian J. Expt. Biol. 38(10):1069-1072.

Murashige T, Skoog F (1962). A revised medium for rapid growth and bioassays with tobacco tissue cultures. Physiol. Plant. 15:473-497.

Sharma N, Chandel KPS (1992). Effects of ascorbic acid on axillary shoot induction in Tylophora indica (Burm. F) Merrill. Plant Cell Tissue Organ Cult. 29:109-113.

Shivpuri DN, Singhal SC, Parkash D (1972). Treatment of asthma with an alcoholic extract of Tylophora indica- a cross-over, double-blind study. An. Allergy. 30(7):407-412.

Suleka Rani JS, Rana (2010). In vitro propagation of Tylophora indicainfluence of explanting season, growth regulator synergy, culture passage and planting substrate. J. Am. Sci. 6(12):385-392.

Thomas T (2009). Isolation, callus formation and plantlet regeneration from mesophyll protoplast of Tylophora indica. In vitro Cell Dev. Boil. plant. 45:591-598. 